\title{
The novel control method of switched reluctance generator
}

\author{
Piotr Bogusz \\ Rzeszow University of Technology \\ Faculty of Electrical and Computer Engineering \\ Wincentego Pola 2, 35-959 Rzeszów, Poland \\ e-mail:pbogu@prz.edu.pl
}

(Received: 04.02.2017, revised: 19.04.2017)

\begin{abstract}
In the paper, a novel control method of a switched reluctance generator was discussed. The presented control method allows a rotor rotating at high speed to enter the continuous-conduction mode which causes an increase of generated output power. A control function of the presented method was given as well as simulation and laboratory tests.
\end{abstract}

Key words: switched reluctance generator, electric vehicle, current control, low speed, high speed

\section{Introduction}

The intensified development of the automotive industry causes that the research on development of travelling comfort, safety improvement and also the decrease of fuel consumption of vehicles and thereby increase of their range on a single tank are being conducted. In the last twenty years, the intensified research is also being conducted on the development of vehicles with an electric drive system due to the development of power electronics systems, control systems as well as the technology of electrochemical accumulators production [1-3]. When an electric motor is used in an electric drive vehicle, the efficiency of electric energy conversion into mechanical energy (during motoring operation) is just as important as conversion of mechanical energy into electric energy (during generating operation). Modern electric drives are supplied with converter systems. Switched reluctance machines are tested, among others, in drives of electric vehicles [4-5]. They are characterized by a simple structure, wide speed range and a high reliability. Unlike drives with combustion engines, merits of electric drives include a bidirectional conversion of energy (electric energy into mechanical energy and mechanical energy into electric energy). Additionally, electric energy can be easily stored in electrochemical accumulators and supercapacitors [6]. The aim of the paper is to present the 
novel control strategy of a SRM in generating operation which allows for the increase of output power and to present results of simulation and laboratory tests.

\section{Mathematical model of SRM}

The equations of mathematical model which takes into account nonlinearity of a magnetic circuit can be written down in the following form:

$$
\begin{gathered}
\boldsymbol{u}=\boldsymbol{R} \boldsymbol{i}+\frac{\mathrm{d}}{\mathrm{d} t}[\boldsymbol{\psi}(\theta, \boldsymbol{i})], \\
J \frac{\mathrm{d} \omega}{\mathrm{d} t}+D \omega+T_{L}=T_{e}, \\
\frac{\mathrm{d} \theta}{\mathrm{d} t}=\omega, \\
T_{e}=\frac{\partial W^{*}(\theta, i)}{\partial \theta},
\end{gathered}
$$

where vectors of voltages $\boldsymbol{u}$, currents $\boldsymbol{i}$, flux-linkages $\boldsymbol{\psi}(\theta, \boldsymbol{i})$ and the matrix of resistances $\boldsymbol{R}$ are defined as: $\boldsymbol{u}=\left[u_{1}, \ldots, u_{N}\right]^{T}, \boldsymbol{i}=\left[i_{1}, \ldots, i_{N}\right]^{T}, \boldsymbol{\psi}(\theta, \boldsymbol{i})=\left[\psi_{1}\left(\theta, i_{1}, \ldots, i_{N}\right), \ldots, \psi_{N}\left(\theta, i_{1}, \ldots, i_{N}\right)\right]^{T}$, $\boldsymbol{R}=\operatorname{diag}\left(R_{1}, \ldots, R_{N}\right)$. Moreover, the following symbols are used in the equations: $\omega-$ the angular velocity of a rotor, $J$ - the moment of inertia, $D$ - the coefficient of viscous friction, $\theta$ - the rotor position, $T_{L}$ - the load torque, $T_{e}$ - the electromagnetic torque, $W^{*}(\theta, i)$ - the coenergy.

\section{The subject of research}

The subject of simulation and laboratory tests is a four-phase $8 / 6$ switched reluctance machine which geometry was shown in Fig. 1. In Table 1, basic parameters of the tested machine were listed.

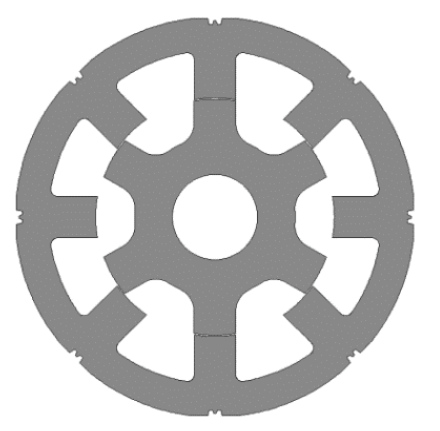

Fig. 1. SRM 8/6: a cross-section 
Table 1. Basic parameters of the SRM

\begin{tabular}{l|c}
\hline Machine type & SRM \\
\hline Number of phases & 4 \\
\hline Number of stator/rotor poles & $8 / 6$ \\
\hline Rated supply voltage & $48 \mathrm{~V}$ \\
\hline Rated power & $3.3 \mathrm{~kW}$ \\
\hline Rated speed & $4500 \mathrm{rpm}$ \\
\hline Maximum phase current & $130 \mathrm{~A}$ \\
\hline
\end{tabular}

It was assumed that the rotor and stator are made from anisotropic M530-50A sheet. The B-H curve of the used sheet was implemented in a resource base of FEM software. The calculations for various currents and rotor position were made based on the loaded data and fluxcurrent-angle and torque-current-angle characteristics were determined. The machine was supplied with a classic H-type half-bridge [7]. The schematic diagram of the motor supply system was shown in Fig. 2. A lead-acid battery of $48 \mathrm{~V}$ rated voltage was used as a voltage source.

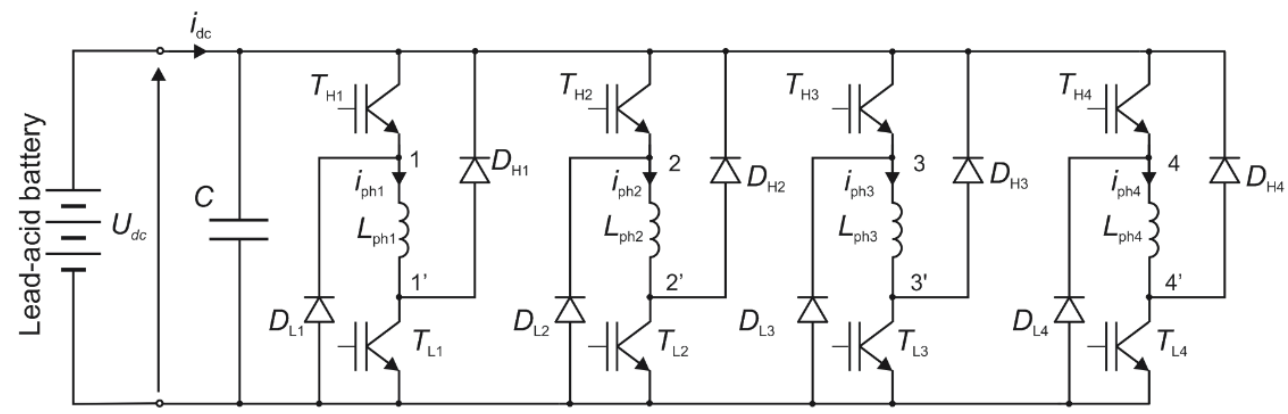

Fig. 2. A schematic diagram of the SRM supply system

\section{Control methods of Switched Reluctance Generator}

\subsection{Generator Classical Current Control (GCCC)}

In electric and hybrid vehicles, an electric machine which operates as a generator is the main system of energy recovery during braking. A control of braking operation of an electric machine allows changing of a braking torque of a vehicle according to the actual position of brake and accelerator pedals. The possibility of mechanical energy conversion into electric energy is limited by both electric machine parameters and parameters of energy storage systems like electrochemical accumulators or hybrid systems (accumulator-supercapacitor) [6]. In classic structures of switched reluctance machines, a current in phases is unidirectional. The energy recovery to supply a source can be obtained during descending the region of a phase inductance when phase voltages are negative. A braking torque of a machine can be changed through proper regulation of phase currents [7-8]. The regulation of phase currents can be 
realized by using current controllers or by changing the turn-on angle $\left(\theta_{\text {on }}\right)$ and turn-off angle $\left(\theta_{\text {off }}\right)$ but without using current controllers [7]. In [9], authors present the current control algorithm of a switched reluctance generator (SRG) which minimizes output current $\left(I_{\mathrm{dc}}\right)$ ripples with simultaneous maximizing of efficiency based on previously registered data. The comparison of SRG properties under discontinuous-conduction mode (DCM) and under continuous-conduction mode (CCM) was presented in [10].

Current regulation is possible when the back-electromotive force (back-EMF) is lower than the dc-link voltage $U_{\mathrm{dc}}$. Such a situation was shown in Fig. 3a. In this case, the current controller is able to maintain the current on the defined level. However, when the back-EMF is higher than the dc-link voltage, the current regulation is not possible. The transistors are switched-off (at point $\theta_{\text {off }(k)}^{i}$ ) by the current controller when the phase current reaches a reference value $\left(I_{\text {ref }}\right)$ which causes the negative voltage on the phase $-U_{\mathrm{dc}}$ until the current falls to zero. In this case, the drive changes operation into the single-pulse mode. Waveforms of the current, voltage and self-inductance of the phase were presented in Fig. 3b.
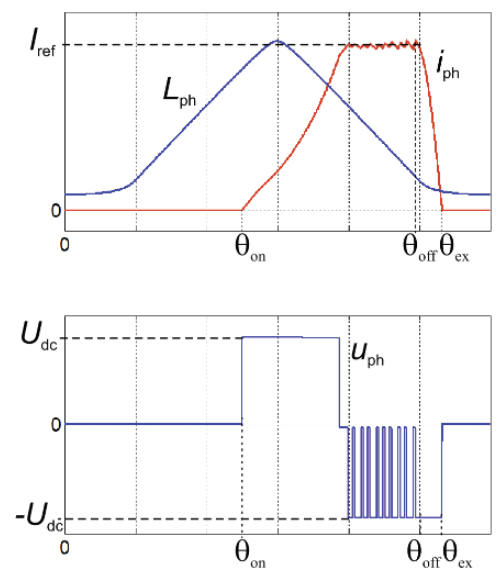

(a)
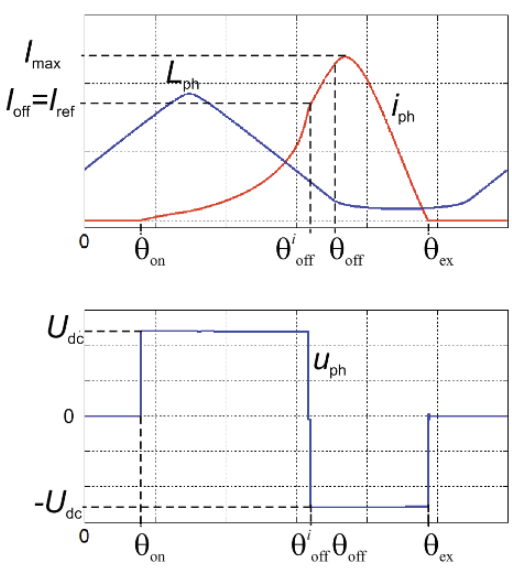

(b)

Fig. 3. Waveforms of self-inductance $\left(L_{\mathrm{ph}}\right)$, current $\left(i_{\mathrm{ph}}\right)$ and phase voltage $\left(u_{\mathrm{ph}}\right)$ under the current control (a); under the single-pulse mode (b)

In the following part of the paper, phase currents were marked according to Fig. 4 as: $i_{\mathrm{ph}(k-1)}-$ the outgoing current, $i_{\mathrm{ph}(k)}-$ the present current and $i_{\mathrm{ph}(k+1)}-$ the incoming current.

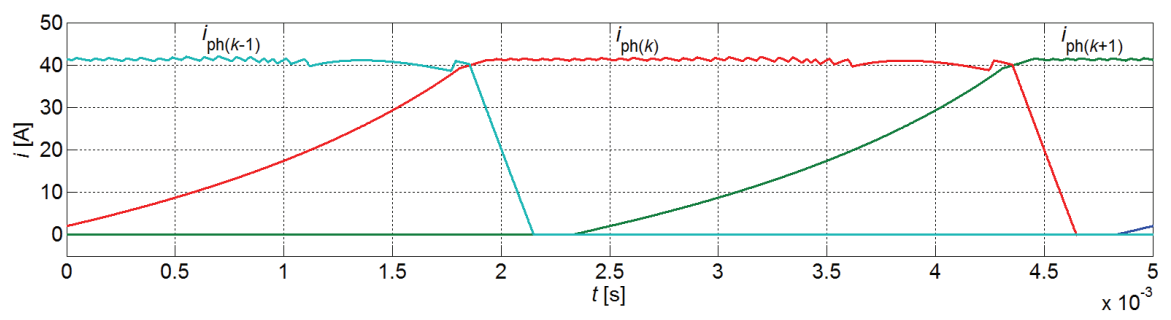

Fig. 4. Designations of phase currents: outgoing $i_{\mathrm{ph}(k-1)}$, present $i_{\mathrm{ph}(k)}$ and incoming $i_{\mathrm{ph}(k+1)}$ 
A control function of a current controller in the whole range of the classic current control GCCC can be described as follows:

$$
S_{(k)}^{\mathrm{GCCC}}=\left\{\begin{array}{cc}
f_{(k)} & \theta_{\mathrm{on}(k)} \leq \theta_{(k)}<\theta_{\mathrm{off}(k)} \\
-1 & \theta_{\mathrm{off}(\mathrm{k})} \leq \theta_{(k)}<\theta_{\mathrm{ex}(k)}
\end{array},\right.
$$

where the function $f_{(k)}$ can be written as:

$$
f_{(k)}=\left\{\begin{aligned}
-1 & \text { if }\left(i_{\mathrm{ph}(k)} \geq I_{\mathrm{ref}}+\Delta i\right) \\
0 & \text { if }\left(I_{\mathrm{ref}}-\Delta i<i_{\mathrm{ph}(k)}<I_{\mathrm{ref}}+\Delta i\right) \\
1 & \text { if }\left(i_{\mathrm{ph}(k)} \leq I_{\mathrm{ref}}-\Delta i\right)
\end{aligned}\right.
$$

and angles $\theta_{\text {on }}$ and $\theta_{\text {off }}$ are turn-on and turn-off angles of the present phase $(k)$, and $\Delta i$ is a range of current hysteresis.

\subsection{Generator dependent current control (GDCC)}

In the paper, the novel function of a current regulation in a generating operation of the SRM, in which the current controller in the outgoing phase $(k-1)$ depends on the current controller in the present phase $(k)$, was proposed. In a conduction period $\left\langle\theta_{\mathrm{on}(k)}, \theta_{\mathrm{off}(k)}\right\rangle$, phase currents controllers operate in the same way like in the GCCC control. It was proposed that instead of the constant value -1 , the control function of current of the outgoing phase $f_{(k-1)}$ during the current decay period should be dependent on the current controller of the present phase $f_{(k)}$. The proposed method was called the generator dependent current control (GDCC). For the proposed control strategy, a shape of a phase current alters according to a working point of the machine. The operation of the SRM can be divided according to a shape of a phase current into:

- the current-control mode,

- the single-pulse mode,

- the continuous-conduction mode.

A control function of the current controller can be written as follows:

$$
S_{(k)}^{\mathrm{GDCC}}=\left\{\begin{array}{cl}
f_{(k)} & \theta_{\text {on }(k)} \leq \theta_{(\mathrm{k})}<\theta_{\text {off }(k)} \\
f_{\text {decay }(k)} & \theta_{\text {off }(k)} \leq \theta_{(\mathrm{k})} \leq \theta_{\text {ex }(k)}
\end{array},\right.
$$

where:

$$
f_{\text {decay }(k)}=\left\{\begin{array}{cc}
0 & \text { if }\left(f_{(k-1)}=-1\right) \\
-1 & \text { if }\left(f_{(k-1)} \neq-1\right)
\end{array},\right.
$$

where the function $f_{(k-1)}$ is analogical to the function $f_{(k)}$ in Equation (6). Waveforms of phase currents and voltages under the control according to the function (7) were shown in Fig. 5. 

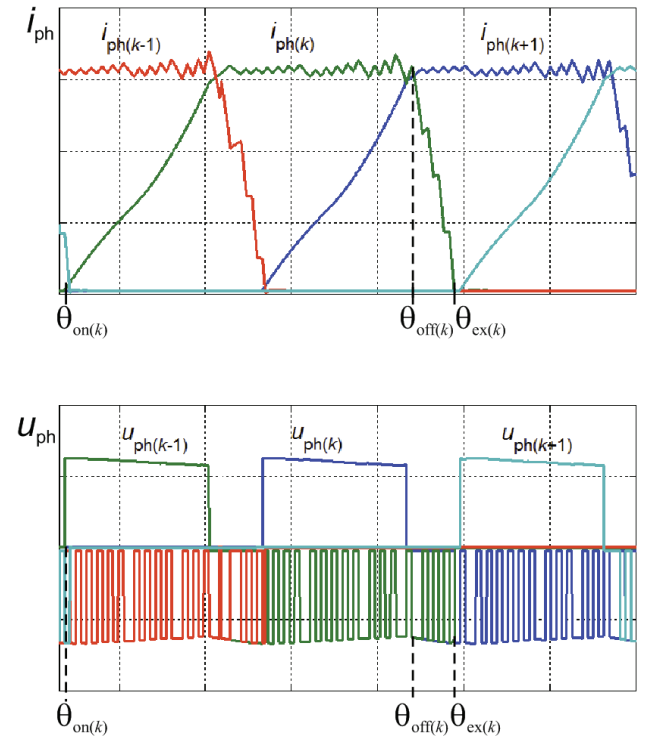

Fig. 5. Waveforms of phase currents $\left(i_{\mathrm{ph}}\right)$ and phase voltages $\left(u_{\mathrm{ph}}\right)$ under the current-control mode

For the single-pulse mode, a control function of the current controller is similar to (7), but an operating period is different. This function can be written as follows:

$$
S_{(k)}^{G D C C}=\left\{\begin{array}{cc}
f_{(k)} & \theta_{\text {on }(k)} \leq \theta_{(k)}<\theta_{\text {off }(k)}^{i} \\
f_{\text {decay }(k)} & \theta_{\text {off }(k)}^{i} \leq \theta_{(\mathrm{k})}<\theta_{\text {ex }(k)}
\end{array},\right.
$$

where the turn-off angle $\theta_{\text {off }(k)}^{i}$ depends on the value of the reference current $I_{\text {ref. }}$ The angle $\theta_{\text {off }(k)}$ should be greater than $\theta_{\text {off }(k)}^{i}$ to generate proper operation of the current controller (Fig. 6). When the current controller in the outgoing phase depends on the current controller in the present phase then a final stage of current falling in the outgoing phase occurs in the zerovolt state and falling time of the current increases. Such a situation causes that the motor enters the continuous-conduction mode much earlier than under the GCCC control (Fig. 7). Therefore, higher output power can be obtained in the same working point compared to the GCCC control. Previous publications have reported that a transition into the continuousconduction mode occurs without the zero-volt state [11-14].

The current controller operation under the continuous-conduction mode can be described by the function:

$$
S_{(k)}^{\mathrm{GDCC}}=\left\{\begin{array}{cc}
f_{(k)} & \theta_{\mathrm{on}(k)} \leq \theta_{(k)} \leq \theta_{\text {off }(k)} \\
f_{\text {decay }(k)} & \theta_{\text {off }(k)}<\theta_{(k)} \leq \theta_{\text {Ioff }(k+1)} \\
0 & \theta_{\text {Ioff }(k+1)} \leq \theta_{(k)} \leq \theta_{\text {on }(k)}+\alpha_{r}
\end{array},\right.
$$

where $\alpha_{r}$ is the rotor pole-pitch. 

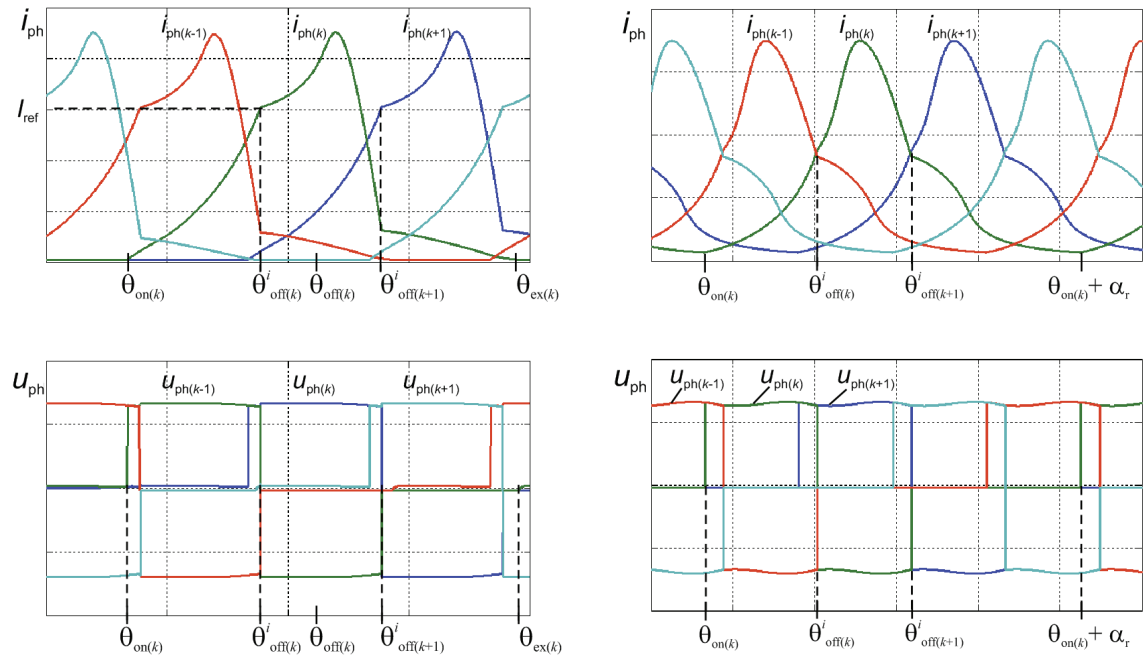

Fig. 6. Waveforms of phase currents $\left(i_{\mathrm{ph}}\right)$ and phase voltages $\left(u_{\mathrm{ph}}\right)$ under the single-

Fig. 7. Waveforms of phase currents

$\left(i_{\mathrm{ph}}\right)$ and phase voltages $\left(u_{\mathrm{ph}}\right)$ under the pulse mode continuous-conduction mode

\section{Simulation tests}

\subsection{The simulation model}

The simulation model of a SRM was built in the Matlab/Simulink environment [15]. The simulation model was realized based on Equations (1)-(4) and flux-current-angle and torquecurrent-angle characteristics which were calculated by means of FEM software. A detailed description of the simulation model was presented in [3]. Waveforms of currents, voltages and torque under the GCCC control and under the proposed GDCC control were registered. The simulation tests were made at low and high speeds. It was assumed that the SRM is supplied from a DC voltage source with a voltage of $54 \mathrm{~V}$. The MOSFET transistors were used due to a low operating voltage of the SRM drive.

\subsection{GCCC control}

The control function described in Equation (7) was implemented in all phases of the SRM simulation model. Fig. 8 shows waveforms of the currents $\left(i_{\mathrm{ph} 1}-i_{\mathrm{ph} 4}\right)$, phase voltages $\left(u_{\mathrm{ph} 1}-u_{\mathrm{ph} 4}\right)$, source current $\left(i_{\mathrm{dc}}\right)$ and motor torque $\left(T_{e}\right)$ at a speed of $n=2000 \mathrm{rpm}$ and a reference current of $I_{\text {ref }}=37.5$ A. As it can be seen in Fig. 8, obtained waveforms have characteristic shape for generating operation of the SRM.

Once the rotor reaches the angle $\theta_{\text {off }}$, the current in the phase decays due to the negative value of the voltage $-U_{\mathrm{dc}}$. Fig. $8 \mathrm{~b}$ shows tristate operation of the current controller. The backEMF increases with the increase of a phase current and/or speed. 


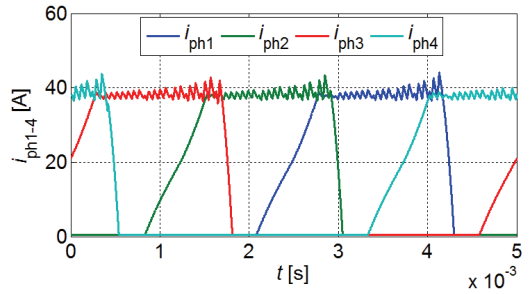

(a)

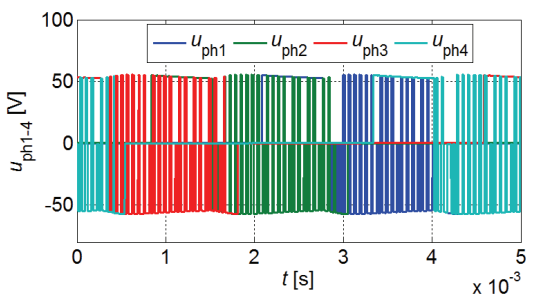

(b)

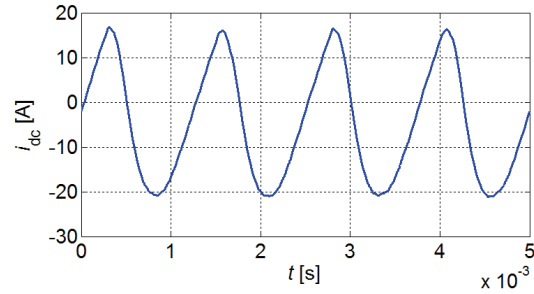

(c)

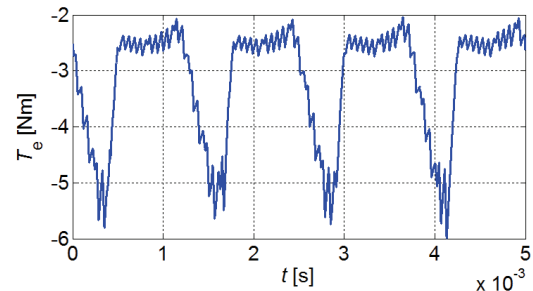

(d)

Fig. 8. Waveforms of phase currents (a); phase voltages (b); source current (c) and electromagnetic torque (d) under the GCCC control

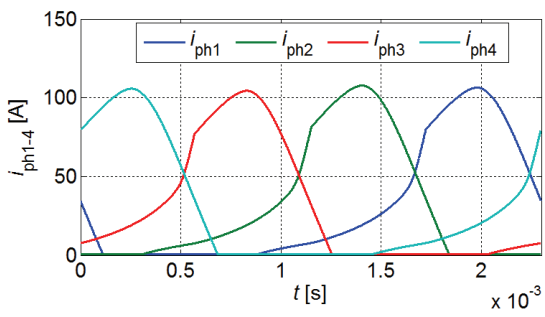

(a)

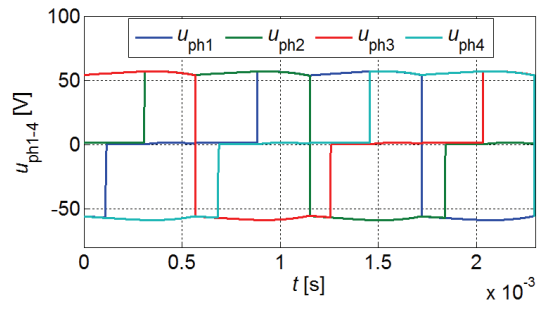

(b)

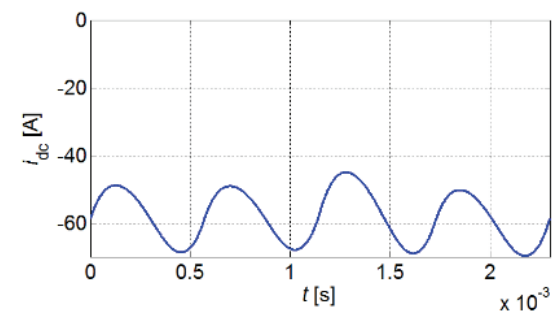

(c)

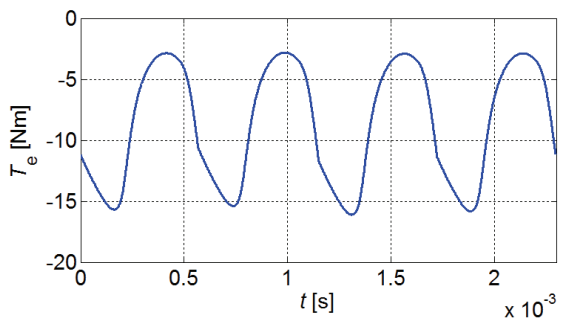

(d)

Fig. 9. Waveforms of phase currents (a); phase voltages (b); source current (c) and electromagnetic torque (d) under the single-pulse mode with a GCCC controller

In the GCCC control, it is not possible to maintain current at the defined value when the back-EMF is higher than $U_{\mathrm{dc}}$ and then the current controller changes the turn-off angle. Waveforms for the above-mentioned working point were shown in Fig. 9. They were determined at a speed of $n=4350 \mathrm{rpm}$ and $I_{\text {ref }}=37.5 \mathrm{~A}$. 


\subsection{GDCC control}

The simulation tests for the GDCC control were conducted at a speed of $n=2000 \mathrm{rpm}$ and a reference current of $I_{\mathrm{ref}}=37.5 \mathrm{~A}$. Fig. 10 shows waveforms of the phase currents $\left(i_{\mathrm{ph} 1}-i_{\mathrm{ph} 4}\right)$, phase voltages $\left(u_{\mathrm{ph} 1}-u_{\mathrm{ph} 4}\right)$, source current $\left(i_{\mathrm{dc}}\right)$ and motor torque $\left(T_{e}\right)$. It can be seen in Fig. 10a that the current decays slower than under the GCCC control (Fig. 8a). It results from a dependence of the current controller of the outgoing phase on the controller of the present phase.

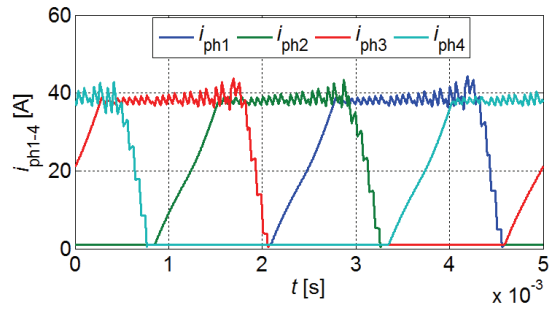

(a)

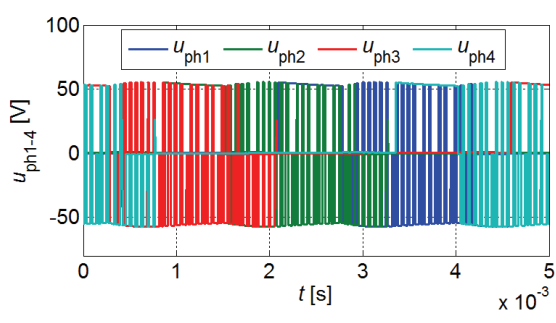

(b)

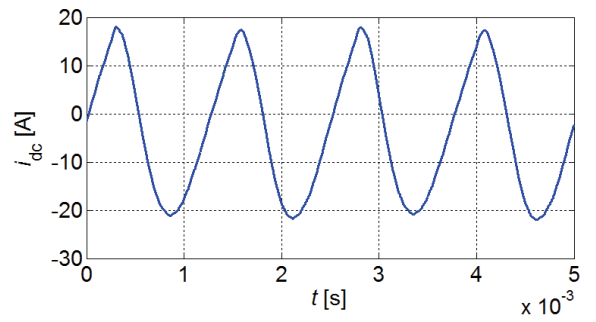

(c)

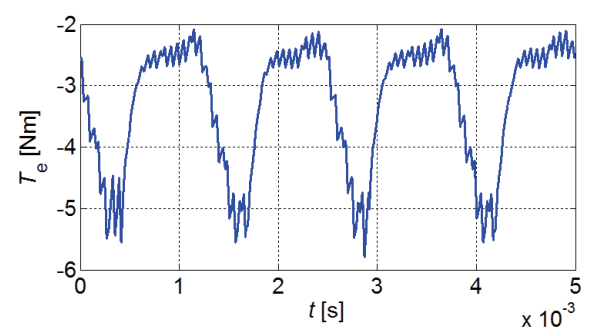

(d)

Fig. 10. Waveforms of phase currents (a); phase voltages (b); source current (c) and electromagnetic torque (d) under the GDCC control

Fig. 11 shows waveforms of the phase currents (Fig. 11a), phase voltages (Fig. 11b), source current (Fig. 11c) and electromagnetic torque (Fig. 11d) under the continuous-conduction mode at a speed of $n=4350 \mathrm{rpm}$ and a reference current of $I_{\mathrm{ref}}=80 \mathrm{~A}$. An increase of speed causes an increase of the back-EMF and an increase of the maximum values of phase currents.

It can be seen in Fig. 11a that the phase current conduction is continuous not discontinuous. It results from the operation of the GDCC current controllers at high instantaneous values of the back-EMF.

\section{Laboratory tests}

The laboratory tests were conducted on the experimental setup which consists of a SRM (with details listed in Table 1) and the commutator DC machine with a power of $4.7 \mathrm{~kW}$. The machines were coupled with a planetary gear and a HBM T22 torque meter. 


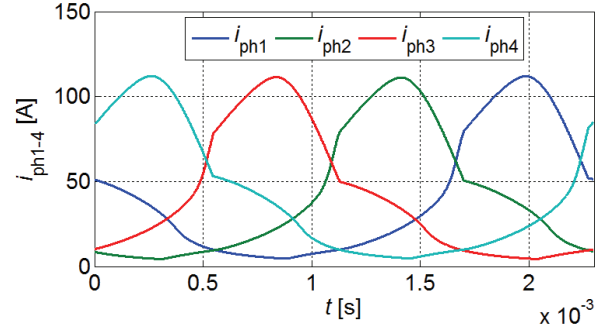

(a)

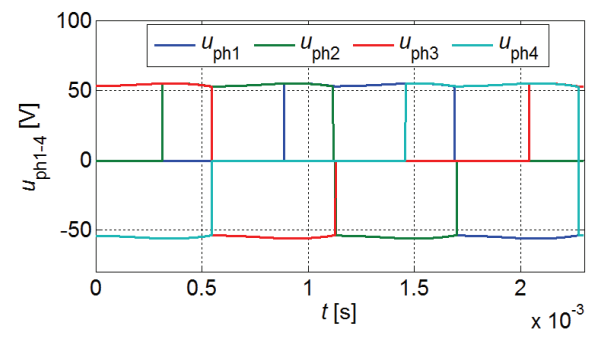

(b)

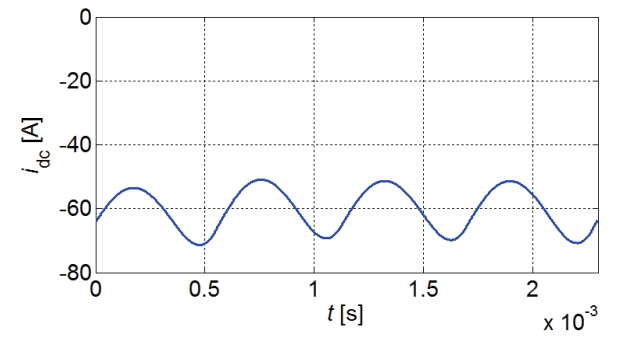

(c)

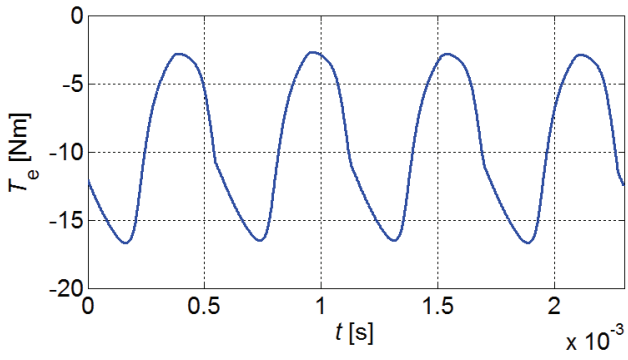

(d)

Fig. 11. Waveforms of phase currents (a); phase voltages (b); source current (c) and electromagnetic torque (d) under the continuous mode with a GDCC controller

The DC machine was supplied from a thyristor controller „Mentor”. The SRM was controlled by the dSPACE's DS1103 card. A lead-acid battery of $48 \mathrm{~V}$ rated voltage and a programmable load (connected in parallel with the accumulator) which operated in the constant voltage mode were used as a load of the SRM. The voltage limit was set to $54 \mathrm{~V}$. The programmable load was used to make results independent of a battery charge status.

(a)

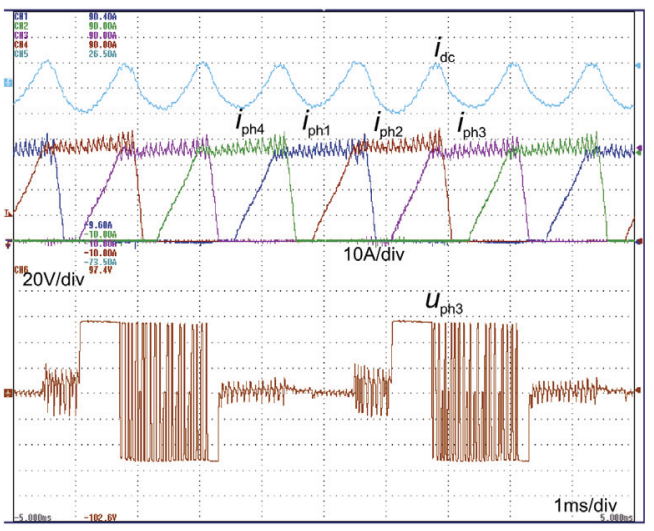

(b)

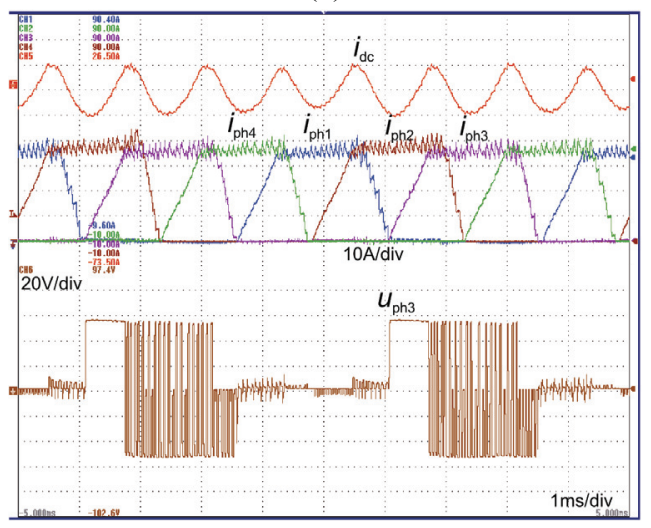

Fig. 12. Waveforms of phase currents, source current and phase voltage at $n=2000 \mathrm{rpm}, I_{\text {ref }}=37.5 \mathrm{~A}$, $U_{\mathrm{dc}}=54 \mathrm{~V}$ - under: the GCCC (a); the GDCC (b) 
Figs. 12 and 13 show oscillograms of the phase currents and phase voltage under the GCCC control and the GDCC control at a speed of $n=2000 \mathrm{rpm}$ and a reference current of $I_{\text {ref }}=37.5 \mathrm{~A}$ (Fig. 12) and at a speed of $n=4350 \mathrm{rpm}$ and a reference current $I_{\text {ref }}=80 \mathrm{~A}$ (Fig. 13). The oscillograms were registered by a DL850 Yokogawa multi-channel scope recorder. It can be seen in Fig. 13 that duration of the negative voltage is longer under the GCCC control than under the GDCC control.

(a)

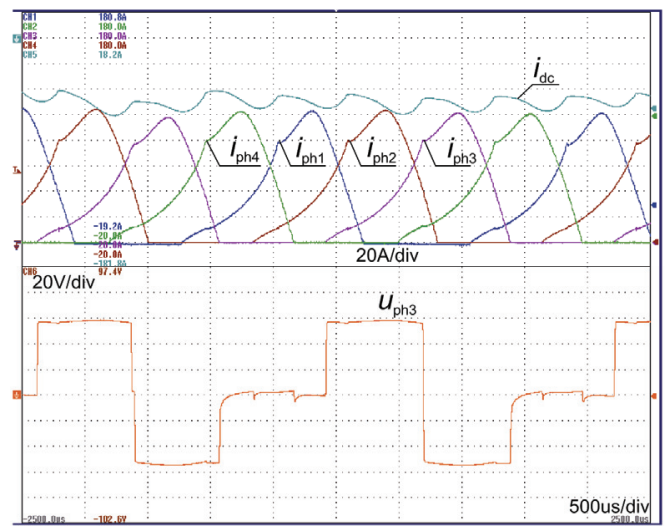

(b)

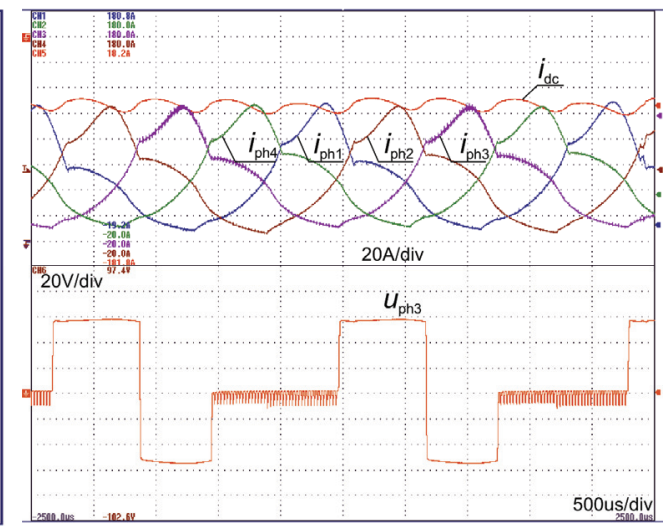

Fig. 13. Waveforms of phase currents, source current and phase voltage at $n=4350 \mathrm{rpm}, I_{\mathrm{ref}}=80 \mathrm{~A}$, $U_{\mathrm{dc}}=54 \mathrm{~V}-$ under the GCCC (a); the GDCC (b),

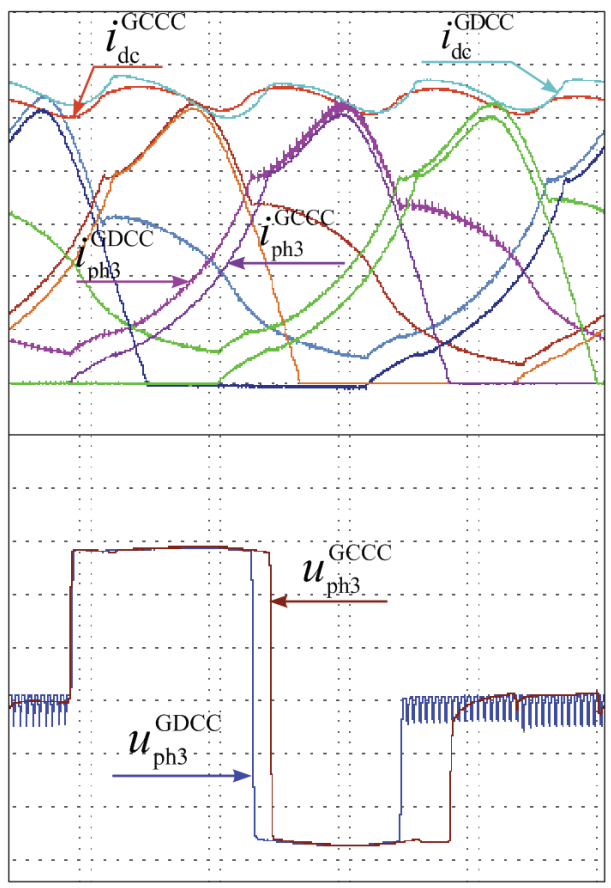

Fig. 14. A comparison of waveforms under the GCCC and the GDCC control 
However, under the GDCC controller it acts earlier than under the GCCC because a phase current reaches earlier the reference value. In the initial stage of the negative voltage appearance, the inductance change of the phase in the function of rotor position is much bigger than in the moment of phase voltage changing from $-U_{\mathrm{dc}}$ to zero (Fig. $5 \mathrm{~b}$ ).

It causes that the amount of generated energy is higher under the GDCC control than under the GCCC control. Fig. 14 shows a comparison of the waveforms of the phase currents, phase voltages and source current for the same operating conditions which were shown in the oscillograms in Fig. 13. The maximum value of phase currents was limited during tests to 120 A due to the maximum permissible currents of controller elements.

(a)

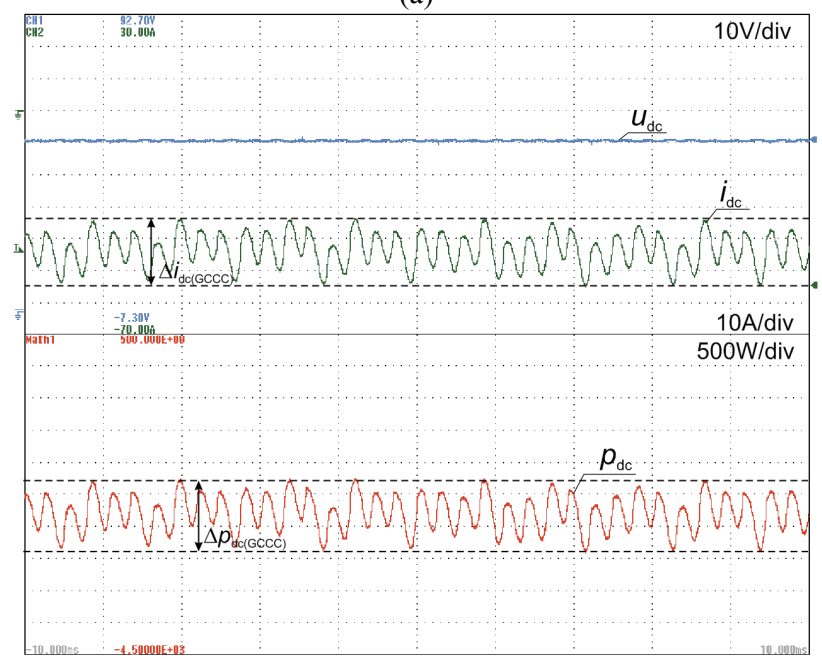

(b)

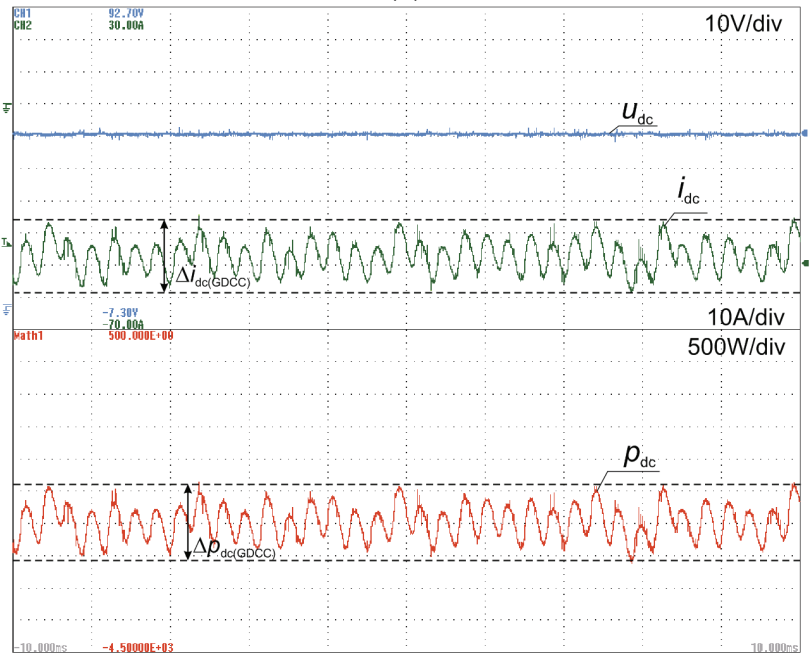

Fig. 15. Waveforms of voltage $u_{\mathrm{dc}}$, current $i_{\mathrm{dc}}$ and output power $p_{\mathrm{dc}}$ under the GCCC (a) and the GDCC (b) 
Fig. 15 shows waveforms of the voltage $u_{\mathrm{dc}}$, current $i_{\mathrm{dc}}$ and output power $p_{\mathrm{dc}}$ under the GCCC (Fig. 15a) and the GDCC (Fig. 15b) at a speed of $n=4500 \mathrm{rpm}$ and a reference current of $I_{\text {ref }}=75 \mathrm{~A}$. A range of voltage change of a battery is almost unnoticeable. As it can be seen, a range of output current $\left(i_{\mathrm{dc}}\right)$ change is about $\Delta i_{\mathrm{dc}(\mathrm{GCCC})}=21.2 \mathrm{~A}$ under the GCCC and $\Delta i_{\mathrm{dc}(\mathrm{GDCC})}=24.4 \mathrm{~A}$ under the GDCC. It considerably affects the output power ripples. A range of instantaneous power change at batteries voltage $U_{\mathrm{dc}}=60 \mathrm{~V}$ was equal to $\Delta p_{\mathrm{dc}(\mathrm{GCCC})}=$ $=1272 \mathrm{~W}$ under the GCCC and $\Delta p_{\mathrm{dc}(\mathrm{GCCC})}=1464 \mathrm{~W}$ under the GDCC. It should be noted that under the GCCC the average output power at this working point was equal to $P_{\mathrm{GCCC}}=2330 \mathrm{~W}$ and under the GDCC it was equal to $P_{\mathrm{GDCC}}=2520 \mathrm{~W}$.

Fig. 16 shows a dependence of the SRG efficiency in the function of output power and the graph of power losses in windings under the GCCC and the GDCC control. By comparing both graphs, it can be seen that despite increasing of winding losses under the GDCC control, the resultant efficiency is almost the same in both cases. It can be seen in Fig. 16a that for the reference current higher than $50 \mathrm{~A}\left(I_{\text {ref }}>50 \mathrm{~A}\right)$ the difference in output power between the GCCC and the GDCC control increases.

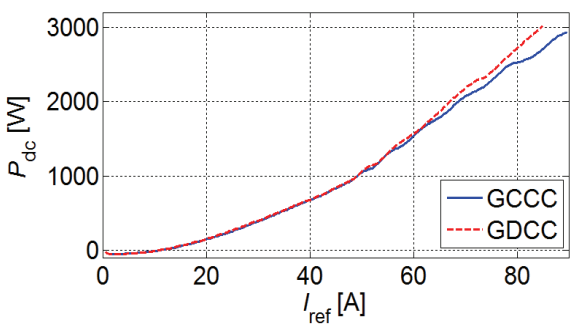

(a)

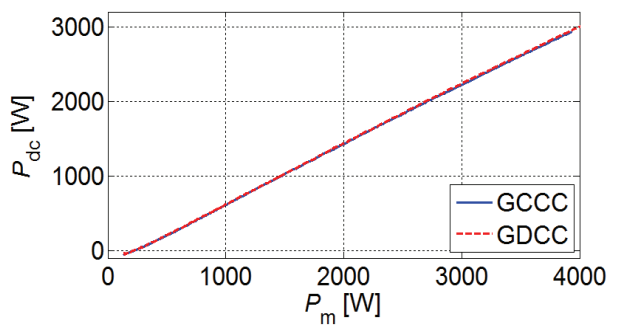

(b)

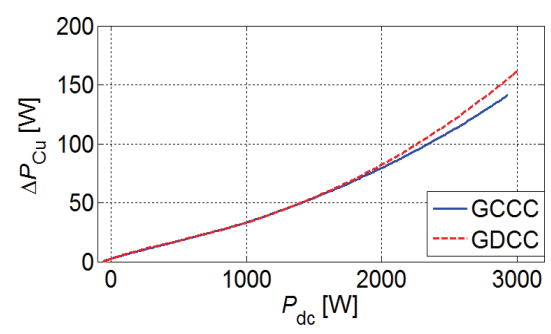

(c)

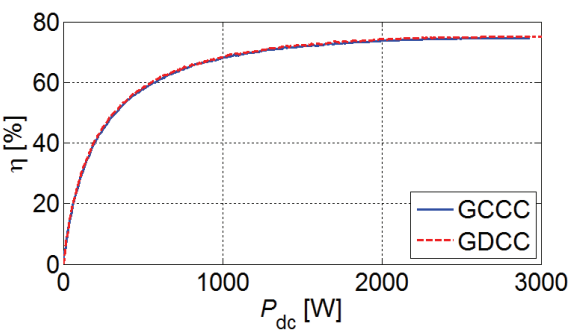

(d)

Fig. 16. Graphs of output power $P_{\mathrm{dc}}$ in the function of reference current $I_{\mathrm{ref}}$ (a); output power $P_{\mathrm{dc}}$ in the function of mechanical power $P_{\mathrm{m}}$ (b); copper losses $\Delta P_{\mathrm{Cu}}$ in the function of output power $P_{\mathrm{dc}}$ (c); drive efficiency $\eta$ in generating operation in the function of output power $P_{\mathrm{dc}}(\mathrm{d})$ under the GCCC and the GDCC control

\section{Conclusions}

In the paper, the novel control strategy of a SRM called the generator dependent current control (GDCC), in which operation of the current controller of the outgoing phase depends on 
the operation of the controller in the incoming phase, was proposed. Such a solution in comparison to the classic current controller (GCCC):

- does not change motor performance under the current control,

- causes that an increase in output power is noticeable as early as half way through the tested range of output power i.e. when phase currents enter continuous conduction mode,

- does not change the efficiency of a machine with a control system.

In general, thanks to the capability of obtaining a higher output power under the continuous-conduction mode, the proposed control method proved advantageous over the GCCC control method. For this reason, the use of an SRM in drives of electric and hybrid vehicles is more profitable. Unfortunately, a high current and output power ripples occur under the GCCC and the GDCC control without any filter systems.

\section{References}

[1] Gasbaoui B., Abdelkader Ch., Adellah L., Multi-input multi-output fuzzy logic controller for utility electric vehicle, Archives of Electrical Engineering, vol. 60, no. 3, pp. 239-256 (2011).

[2] Adamczyk D., Wilk A., Michna M., Model of the double-rotor induction motor in terms of electromagnetic differential, Archives of Electrical Engineering, vol. 65, no. 4, pp. 761-772 (2016).

[3] Bogusz P., A switched reluctance motor control method limiting the maximum dc source current in the low-speed range, Bulletin of the Polish Academy of Sciences Technical Sciences, vol. 64, no. 1, pp. 197-206 (2016).

[4] Chiba A., Takeno M., Hoshi N., Takemoto M., Ogasawara S., Rahman, M.A., Consideration of Number of Series Turns in Switched-Reluctance Traction Motor Competitive to HEV IPMSM, IEEE Transactions on Industry Applications, vol. 48, no. 6, pp. 2333-2340 (2012).

[5] Faiz J., Moayed-Zadeh K., Design of switched reluctance machine for starter/generator of hybrid electric vehicle, Electric Power Systems Research no. 75, Elsevier, pp. 153-160 (2005).

[6] Baoming G., de Almeida A.T., Ferreira F.J.T.E., Supercapacitor-based optimum switched reluctance drive for advanced electric vehicles, in IEEE International Conference on Electrical Machines and Systems, vol. 1, pp. 822-827 (2005), DOI: 10.1109/ICEMS.2005.202652.

[7] Miller T.J.E., Electronic Control of switched reluctance machines, Newnes (2001).

[8] Kosmatin P., Miljavec D., Vončina D., A novel control strategy for the switched reluctance generator, Przegląd Elektrotechniczny, vol. 88, no. 7a, pp. $49-53$ (2012).

[9] Sikder Ch., Husain I., Sozer Y., Switched Reluctance Generator Control for Optimal Power Generation With Current Regulation, IEEE Transactions on Industry Applications, vol. 50, no. 1, pp. 307-316 (2014).

[10] Hannoun H., Hilairet M., Marchand C., Experimental Validation of a Switched Reluctance Machine Operating in Continuous-Conduction Mode, IEEE Transactions on Vehicular Technology, vol. 60, no. 4, pp. 1453-1460 (2011).

[11] Nuwantha F., Control of Switched Reluctance Generators in Continuous Conduction Mode, IEEE Energy Conversion Congress and Exposition (ECCE), pp. 1360-1365 (2014), DOI: 10.1109/ECCE. 2014.6953576.

[12] Vujičić V.P., Ćalasan M.P., Simple Sensorless Control for High-Speed Operation of Switched Reluctance Generator, IEEE Transactions on Energy Conversion, vol. 31, no. 4, pp. 1325-1335 (2016).

[13] Korkosz M., Mazur D., Operation of the switched reluctance motor at continuous conduction of phase current, IEEE Mediterranean Electrotechnical Conference - MELECON 2006, pp. 1166-1169 (2006), DOI: 10.1109/MELCON.2006.1653308.

[14] Korkosz M., Bogusz P., Pilecki M., The impact of parameter control on the characteristics of switched reluctance motor designed for small electric vehicle drive, Selected Problems of Electrical Engineering and Electronics (WZEE), pp. 1-4 (2015), DOI: 10.1109/WZEE.2015.7394044.

[15] Matlab/Simulink R2012a-User's Guide, Mathworks (2012). 